\title{
Thermal Strength Characteristics and Mechanism of Iron Ore and Carbon Pellets in the Non-isothermal Reduction Process
}

\author{
Qingmin MENG, ${ }^{1)}$ Rufei WEI, ${ }^{1)}$ Jiaxin $\mathrm{LI}^{1,3)}$ Ping WANG, ${ }^{1)}$ Zhifang GAO, ${ }^{1,2)}$ Zhanxia $\mathrm{DI}^{1)}$ and Hongming LONG ${ }^{1,2) *}$ \\ 1) School of Metallurgical Engineering, Anhui University of Technology, Ma'anshan, Anhui, 243002 China. \\ 2) Key Laboratory of Metallurgical Emission Reduction \& Resources Recycling, Ministry of Education, Anhui University of \\ Technology, Ma'anshan, Anhui, 243002 China. \\ 3) School of Metallurgy, Northeastern University, Shenyang, 110819 China.
}

(Received on April 25, 2017; accepted on November 10, 2017; J-STAGE Advance published date: February 7, 2017)

\begin{abstract}
The thermal strength characteristics and mechanism of iron ore and carbon pellets (ICP) in the non-isothermal heating process, including the effect of reducing agent, carbon content and heating rate on the thermal strength, were studied by the on-line test device of thermal strength, combined with the TG/DTG-DTA data, the samples microstructure and porosity after reduction. When ICP was damaged by external force at high temperatures, it existed in two states: crush and plastic deformation. The thermal strength of ICP slightly increased at $200^{\circ} \mathrm{C}-800^{\circ} \mathrm{C}$, significantly decreased after $800^{\circ} \mathrm{C}$ and reached the minimum value at $1000^{\circ} \mathrm{C}$. The thermal strength of ICP was changed by the combination of combined water evaporation, the reducing agent volatilization and the reduction reaction. At $200^{\circ} \mathrm{C}-1000^{\circ} \mathrm{C}$, the thermal strength was derived from the molecular attraction between the particles and viscous force from bonding agent. But when the temperature higher than $1000^{\circ} \mathrm{C}$, the thermal strength was served by metal iron continuous crystal. To obtain high thermal strength, the iron oxides in ICP should be reduced fast by using the reducing agent with low volatility, improving the heating rate and choosing the suitable reducing agent ratio, made the iron crystal grown rapidly and dense.
\end{abstract}

KEY WORDS: thermal strength; iron ore and carbon pellets; non-isothermal reduction; porosity; microstructure.

\section{Introduction}

Iron ore and carbon pellets (ICP), as a new ironmaking raw materials with good reduction properties, provides some possibilities for the new processes development, such as the production of metallized raw materials, the treatment of steel waste containing Fe and the dressing of complex refractory ore. ${ }^{1-3)}$ Many works have been done referring to the reduction mechanism of $\mathrm{ICP}^{4-13)}$ and the strength of ICP after reduction, ${ }^{14,15)}$ providing an important support for the development and application of ICP. Jung et al. ${ }^{4)}$ found the critical temperature of carbon gasification was $1055^{\circ} \mathrm{C}$ in the carbothermic reduction of magnetite by TGA-DSC-QMS. Liu et al. ${ }^{8)}$ studied the reduction reaction of vanadium and titanium iron concentrate pellets containing carbon, and found that the reaction process was divided into two stages, and the velocity of later reaction was less than that of the early reaction. Furthermore, M.S. Chu et al. ${ }^{5)}$ Y. Ueki et $a l .{ }^{6)}$ and Y. Matsui et al. ${ }^{7)}$ reported the reducing and melting behavior of carbon composite iron ore hot briquette $(\mathrm{CCB})$. The reduction of $\mathrm{CCB}$ is controlled by the step of gas inner diffusion through the layer of reduction

* Corresponding author: E-mail: yaflhm@126.com

DOI: http://dx.doi.org/10.2355/isijinternational.ISIJINT-2017-202 iron product. In addition, in order to describe the influences of raw material, heat transfer and solid phase reaction on the reduction process of ICP, many studies were carried out by numerical modeling. ${ }^{10-13)}$

In addition to the reduction mechanism, the strength of ICP is also critical to the selection and production efficiency of the reactor, involving three stages: green ball preparation, preheating drying and high temperature reduction. Generally, the green pellet strength of ICP is very low, at $30 \mathrm{~N}-350 \mathrm{~N}^{18)}$ But the strength of ICP become higher after the reduction, at $1000 \mathrm{~N}-3500 \mathrm{~N}^{15,18)}$ The strength of wet ICP mainly depends on capillary force, and that of preheated ICP mainly depends on chemical adsorption, followed by viscous force. The metallized pellet strength is controlled as per the growth and spread of the iron joined crystals. The residual volatile matter in the semi-charcoal also can conducive to improving the strength of the metallized ICP. ${ }^{14)}$ However, most of the researches on the strength of ICP are focused on the green pellet or after reduction. There are few researches on the thermal strength. Actually, in the high temperature reduction stage, the physical structure of the pellet is changed by the multiple effects of free water evaporation, reducing agent gasification and iron oxide reduction. If the pellet does not have enough strength, the damage or collapse appearance will occur in the pellet, producing a 
very negative impact on the industrial production of the pellets. In this paper, thermal strength characteristics and mechanism of ICP in the non-isothermal reduction process were studied, using the samples made from bituminous coal, anthracite and coke powder with iron ore powder.

\section{Experimental}

\subsection{Materials}

The chemical compositions of iron ore powder used in the experiments were shown in Table 1. Bituminous coal, anthracite and coke powder were used as the reducing agent and their proximate analysis were shown in Table 2.

\subsection{Methods}

First, the samples was dried for 2 hours at $105^{\circ} \mathrm{C}$, and

Table 1. Chemical compositions of iron ore (wt $\%)$.

\begin{tabular}{cccccccc}
\hline $\mathrm{TFe}$ & $\mathrm{FeO}$ & $\mathrm{SiO}_{2}$ & $\mathrm{Al}_{2} \mathrm{O}_{3}$ & $\mathrm{CaO}$ & $\mathrm{MgO}$ & $\mathrm{P}$ & $\mathrm{S}$ \\
\hline 61.40 & 23.52 & 3.30 & 1.05 & 1.00 & 0.20 & 0.028 & 0.328 \\
\hline
\end{tabular}

Table 2. Proximate analysis of reducing agent (wt $\%)$.

\begin{tabular}{cccccc}
\hline Type of reducing agent & Fixed Carbon & Ash & Volatile & P & S \\
\hline Bituminous coal & 61.36 & 4.85 & 32.69 & 0.021 & 0.34 \\
Anthracite & 78.77 & 13.29 & 6.37 & 0.024 & 0.58 \\
Coke & 82.46 & 12.35 & 4.13 & 0.022 & 0.92 \\
\hline
\end{tabular}

then sent to a ball mill to grind until the particle size $\leq$ $74 \mu \mathrm{m}$ for iron ore and $\leq 200 \mu \mathrm{m}$ for the reducing agents. The powder materials are weighed according to the experimental plan as given in Table 3. The ICP samples were made with the diameter range of $12-15 \mathrm{~mm}$ on a disc pelletizer, and the pelletizer speed and angle were set as $60 \mathrm{r} / \mathrm{min}$ and $45^{\circ}$ respectively.

The thermal strength of ICP was studied via the device shown in Fig. 1. The device is mainly composed of a heating furnace, temperature control system, a load control system, an atmosphere control system and a data acquisition system. The working temperature is $25-1400^{\circ} \mathrm{C}$ with \pm $1^{\circ} \mathrm{C}$ temperature control accuracy and $50^{\circ} \mathrm{C} / \mathrm{min}$ maximum heating rate. The thermal strength of ICP will be higher than green pellets and preheated pellets, but much lower than the strength of ICP after reduction, because there is no cold metal iron appears at high temperature. So, the maximum pressure in this experiment is set as $1000 \mathrm{~N}$ and the measurement accuracy is $0.1 \mathrm{~N}$. For each test, the furnace was heated to the setting temperatures $\left(400^{\circ} \mathrm{C}, 600^{\circ} \mathrm{C}, 800^{\circ} \mathrm{C}\right.$, $1000^{\circ} \mathrm{C}, 1200^{\circ} \mathrm{C}$ ) under $\mathrm{N}_{2}$ with $1 \mathrm{~L} / \mathrm{min}$. Then the thermal strength of sample was tested at the same gas atmosphere for 10 times under the same conditions and the average of the 10 measurements was selected as the thermal strength for this conditions.

The thermoset analysis of the samples was performed at the thermal analyzer (France Setaram, Setys EVO) and the microstructure of the samples was analyzed at the scanning electron microscope (Japan JSM, 6490LV).

Porosity of ICP after reaction was measured by appar-

Table 3. Raw material ratio for different ICP.

\begin{tabular}{|c|c|c|c|c|c|c|c|}
\hline Number & Bituminous coal & Anthracite & Coke powder & Iron ore powder & Bentonite & Moisture & Ratio of $\mathrm{C}_{\text {fix }} / \mathrm{O}_{\text {iron oxide }}$ \\
\hline $1 \#$ & $20.68 \%$ & - & - & $79.32 \%$ & $2.0 \%$ & $9.00 \%$ & 0.9 \\
\hline $2 \#$ & $22.46 \%$ & - & - & $77.54 \%$ & $2.0 \%$ & $9.15 \%$ & 1.0 \\
\hline $3 \#$ & $24.17 \%$ & - & - & $75.83 \%$ & $2.0 \%$ & $9.25 \%$ & 1.1 \\
\hline $4 \#$ & - & $18.41 \%$ & - & $81.59 \%$ & $2.0 \%$ & $9.12 \%$ & 1.0 \\
\hline $5 \#$ & - & - & $17.73 \%$ & $82.27 \%$ & $2.0 \%$ & $9.10 \%$ & 1.0 \\
\hline
\end{tabular}

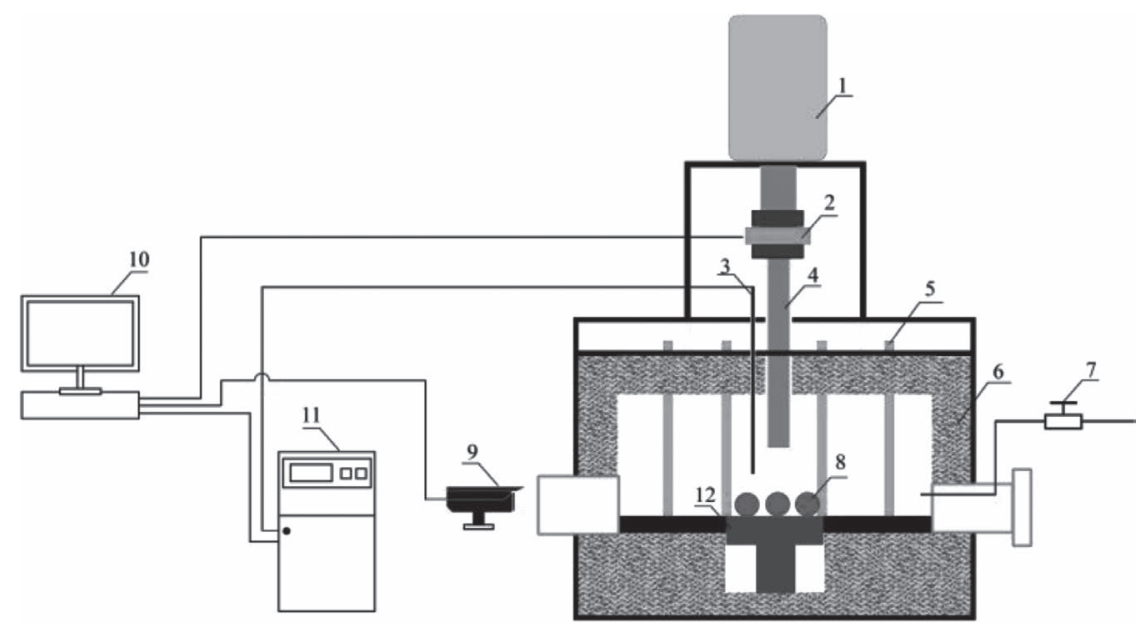

Fig. 1. Schematic diagram of thermal strength test device for ICP in the reduction process. 1 Servo motor, 2 Pressure sensors, 3 Thermocouple, 4 Press bar, 5 Heating element, 6 Heating furnace, 7 Gas mass flow controller, 8 ICP, 9 Camera, 10 Computer data acquisition, 11 Temperature controller, 12 Rotate sample table. 
ent porosity-bulk density analyzer (XQK-02). First, the dry weight $\mathrm{m}_{1}$ of ICP was measured, and then the sample was place into the vacuum hood of the bulk density analyzer for vacuum pumping and injection operation. After that the sample was taken out and the suspended weight $\mathrm{m}_{2}$ and saturate weight $\mathrm{m}_{3}$ were measured in the water. At last, the apparent porosity $\pi$ was calculated by

$$
\pi(\%)=\left(\mathrm{m}_{3}-\mathrm{m}_{1}\right) \times 100 \% /\left(\mathrm{m}_{3}-\mathrm{m}_{2}\right)
$$

\section{Results and Discussion}

\subsection{Morphology of ICP in the Load Reduction Process at High Temperature}

Figure 2 shown the apparent morphology of the sample during the thermal strength test. As shown in Fig. 2(a), when the experimental condition was met, the load control system of the device was activated and transferred pressure to the pellet by press bar. When the pellet was pressed, the pressure changed continuously. The press increased at first and then suddenly drops rapidly. At this time, the pressure was stopped, and the maximum pressure of the process was taken as the thermal strength of ICP. Combining with Figs. 2(b) and 2(c), it can be seen that the ICP kept as a ball before the pressure, and it began to be cracked and crushed once the pressure was applied, but the ICP appeared different forms when it is subjected to external forces until destroyed in different test temperatures. At $200^{\circ} \mathrm{C}-1000^{\circ} \mathrm{C}$, the sample was crushed after compression, forming several small particles. But after $1000^{\circ} \mathrm{C}$, the sample undergone plastic deformation under the action of external force and presented a cake shape after cooling.

\subsection{Thermal Strength of ICP in the Reduction Process}

Figure 3 given the thermal strength test results of ICP using different reducing agents in the reduction process. It can be seen that the thermal strength of pellets with anthracite and bituminous coal increased slightly compared with
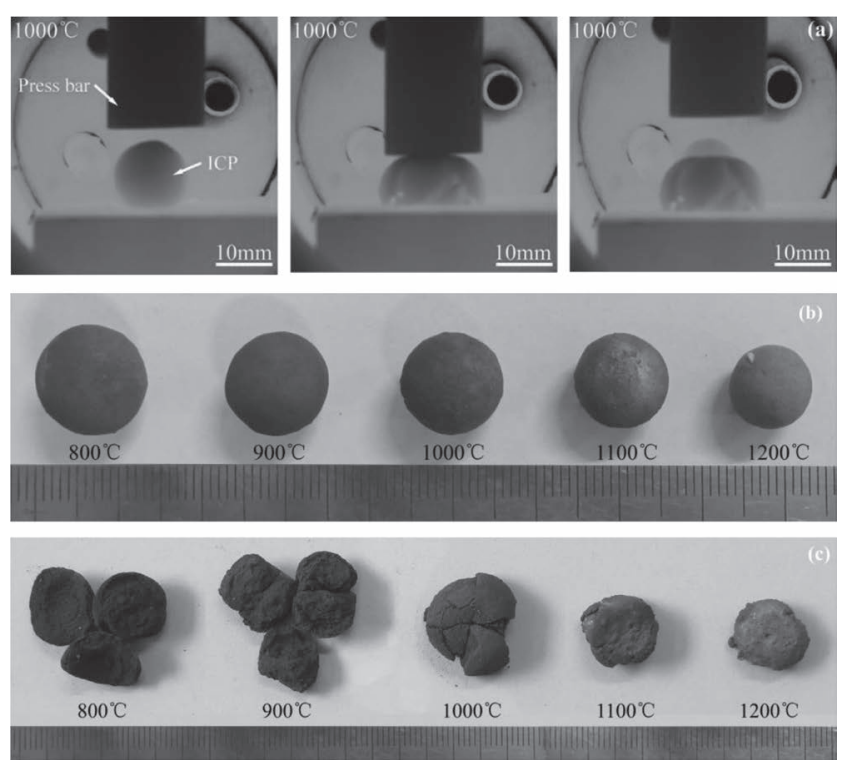

Fig. 2. Normal morphology of samples before and after thermal test of non-isothermal reduction process of ICP (heating rate $\left.20^{\circ} \mathrm{C} / \mathrm{min}\right)$. their dry strength at $200^{\circ} \mathrm{C}-800^{\circ} \mathrm{C}$, maintaining at $20 \mathrm{~N}-30$ $\mathrm{N} /$ pellet. The thermal strength of pellets with coke powder increased with the temperature, and reached $61.8 \mathrm{~N} /$ pellet at $800^{\circ} \mathrm{C}$. At $800^{\circ} \mathrm{C}-1000^{\circ} \mathrm{C}$, the thermal strength of three kinds of ICP decreased rapidly with the increase of temperature. The lowest strength of the pellets with bituminous coal, anthracite and coke powder were $5.5 \mathrm{~N} /$ pellet, $8.5 \mathrm{~N} /$ pellet and $7.5 \mathrm{~N} /$ pellet respectively. At $1000^{\circ} \mathrm{C}-1200^{\circ} \mathrm{C}$, the thermal strength of three kinds of ICP increased rapidly with the temperature rising.

The thermal strength test results of pellets with bituminous coal at different heating rates were shown in Fig. 4. As can be seen from the figure, the change trends of thermal strength at different heating rates were similar, indicating that the effect of heating rate on the thermal strength was not obvious. Figure 5 shown the thermal strength test results of ICP with bituminous at different ratios of carbon and oxygen $(\mathrm{C} / \mathrm{O})$. The change trends of thermal strength at different $\mathrm{C} / \mathrm{O}$ ratios were also similar. Before $800^{\circ} \mathrm{C}$, the thermal strength of the pellets decreased with the increase of the carbon-oxygen ratio. After $800^{\circ} \mathrm{C}$, the thermal strength of the pellets was almost the same, except the thermal strength at $0.9 \mathrm{C} / \mathrm{O}$ ratio was lower than that at the other $\mathrm{C} / \mathrm{O}$ ratios.

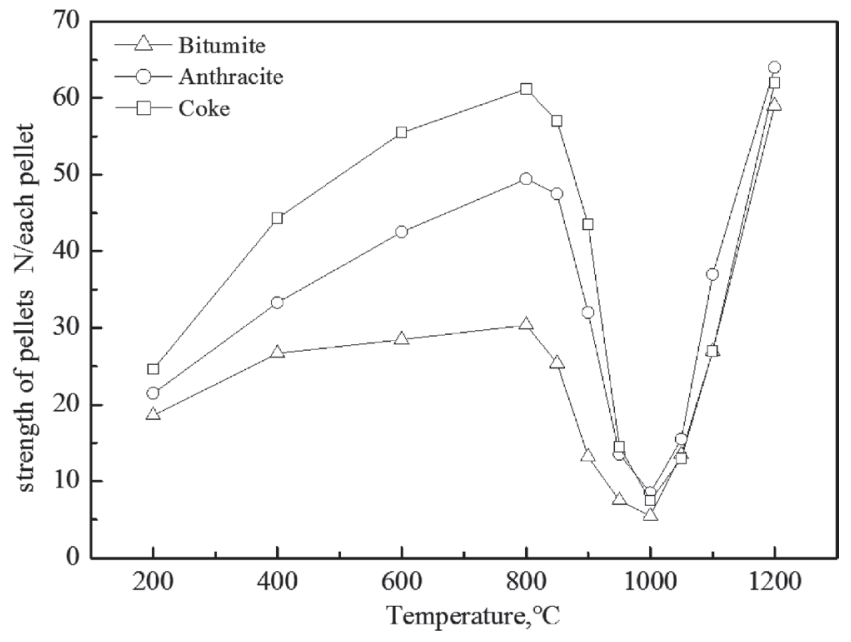

Fig. 3. Thermal strength of non-isothermal reduction process of different reducing agent ICP (heating rate $20^{\circ} \mathrm{C} / \mathrm{min}$ ).

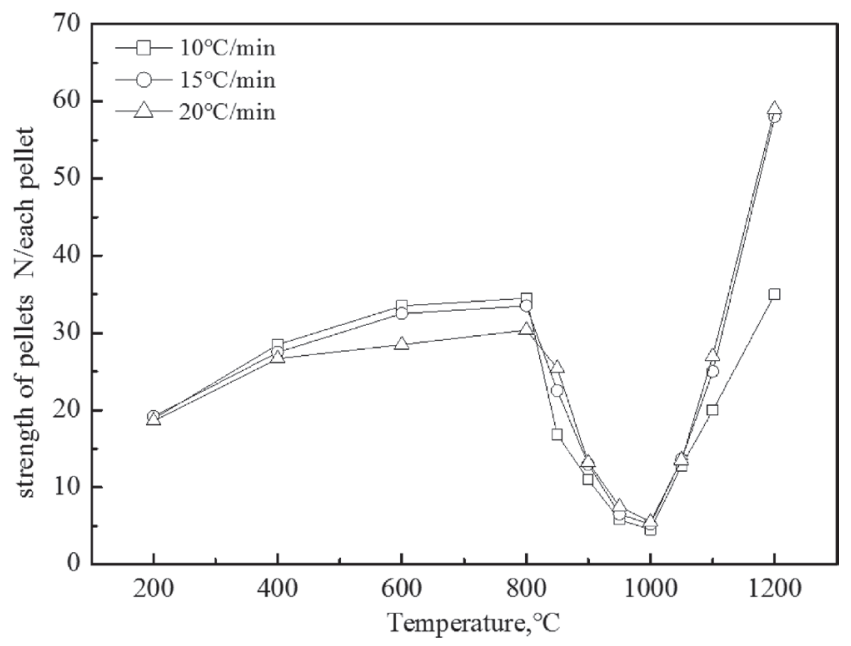

Fig. 4. Thermal strength of non-isothermal reduction process of bituminous ICP at different heating rates. 


\subsection{Effect of Reduction Reaction on the Thermal Strength}

To explore the mechanism of thermal strength of ICP, the thermogravimetric analysis of ICP was carried out under argon conditions at $30 \mathrm{ml} / \mathrm{min}$ and the heating rate was set at $20^{\circ} \mathrm{C} / \mathrm{min}$. The non-isothermal reduction curves of TG/DTG - DTA of ICP with different reducing agents were shown in Fig. 6. The reduction of ICP with different reducing agents was different. The weight of ICP with bituminous, anthracite and coke lost slowly at $225^{\circ} \mathrm{C}-580^{\circ} \mathrm{C}$, $325^{\circ} \mathrm{C}-675^{\circ} \mathrm{C}$ and $475^{\circ} \mathrm{C}-875^{\circ} \mathrm{C}$, respectively. The maximum weight loss ratios of them were $5.15 \%, 4.01 \%$ and $4.08 \%$, respectively. At this stage, the weight loss was due to the combination of combined water evaporation, the reducing agent volatilization and the reduction reaction. The main reduction reaction at this stage was $\mathrm{Fe}_{2} \mathrm{O}_{3} \rightarrow \mathrm{Fe}_{3} \mathrm{O}_{4}$. $\left.{ }^{16}\right)$ After that, the reduction of iron ore by the volatile matter occurred strongly when the temperature reached $750^{\circ} \mathrm{C}$ for the pellets with bituminous coal, $870^{\circ} \mathrm{C}$ for the pellets with anthracite and $925^{\circ} \mathrm{C}$ for the pellets with coke powder, respectively. ${ }^{1)}$ And the main reduction reaction at this stage was $\mathrm{Fe}_{3} \mathrm{O}_{4} \rightarrow \mathrm{FeO}^{16}$ ) After that the weight loss rate increased and reached the maximum at $1002^{\circ} \mathrm{C}, 1140^{\circ} \mathrm{C}$ and $1150^{\circ} \mathrm{C}$ for three kinds of pellets. Near these tem-

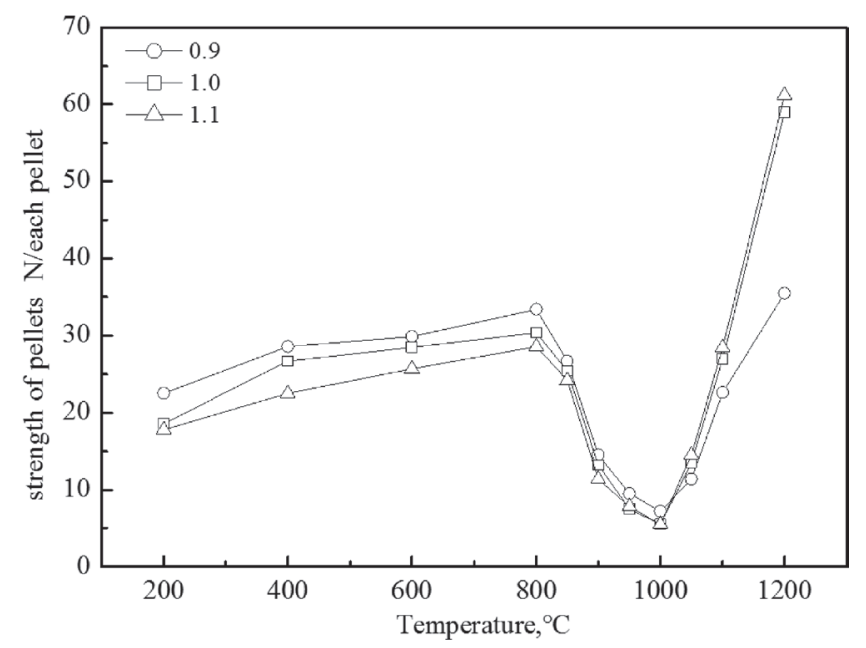

Fig. 5. Thermal strength (heating rate $20^{\circ} \mathrm{C} / \mathrm{min}$ ) of non-isothermal reduction process of bituminous ICP with different ratios of $\mathrm{C}_{\text {fix }} / \mathrm{O}_{\text {iron oxide. }}$

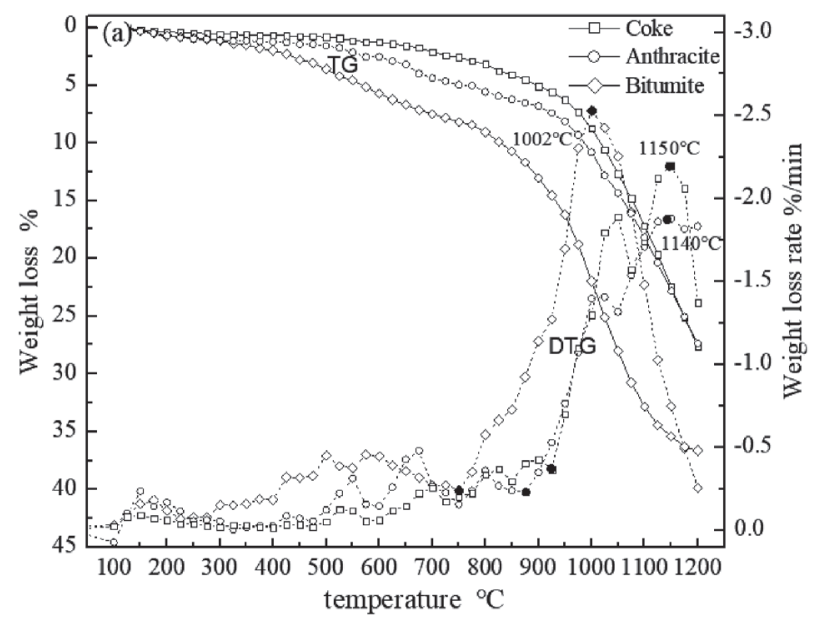

peratures, the endothermic peak of DTA curve appears at $1010^{\circ} \mathrm{C}, 1066^{\circ} \mathrm{C}$ and $1083^{\circ} \mathrm{C}$ successively, indicating that the endothermic reaction occurred at this stage. The main reduction reaction at this stage was $\mathrm{FeO} \rightarrow \mathrm{Fe}^{16)}$ After the temperature reached $1200^{\circ} \mathrm{C}$, the mass loss was slowed down, and the reduction was almost over.

Compared with the thermal strength curve (shown in Fig. 3) and the TG-DTG curve (shown in Fig. 6) of the ICP, it can be found that there was an extreme point in the two curves at about $1000^{\circ} \mathrm{C}$, indicating that the thermal strength was related to the reduction reaction. Before $1000^{\circ} \mathrm{C}$, the reduction rate increased with the temperature, and the mainly reaction is $\mathrm{Fe}_{2} \mathrm{O}_{3} \rightarrow \mathrm{Fe}_{3} \mathrm{O}_{4} \rightarrow \mathrm{FeO} .{ }^{16)}$ The reaction products were mainly $\mathrm{FeO}$ whose melting point is $1360^{\circ} \mathrm{C}$ much lower than that of $\mathrm{Fe}_{3} \mathrm{O}_{4}\left(1538^{\circ} \mathrm{C}\right), \mathrm{Fe}_{2} \mathrm{O}_{3}\left(1565^{\circ} \mathrm{C}\right)$ and $\mathrm{Fe}\left(1535^{\circ} \mathrm{C}\right)$. In addition, $\mathrm{FeO}$ was also easy to form low melting point matter with the gangue composition, such as $2 \mathrm{FeO} \cdot \mathrm{SiO}_{2}-2 \mathrm{CaO} \cdot \mathrm{SiO}_{2}$ and $2 \mathrm{FeO}-2 \mathrm{CaO} \cdot \mathrm{SiO}_{2}$, whose respective melting point are $1150^{\circ} \mathrm{C}$ and $1250^{\circ} \mathrm{C} .{ }^{17)} \mathrm{So}$, at this temperature ICP was easy to soften, and then affecting the thermal strength of pellet. Therefore, the thermal strength of ICP produced a trough at about $1000^{\circ} \mathrm{C}$. The thermal strength of pellet at $1000^{\circ} \mathrm{C}$ was only about $10 \mathrm{~N} /$ pellet, much lower than that at $800^{\circ} \mathrm{C}(25-60 \mathrm{~N} /$ pellet $)$ and $1200^{\circ} \mathrm{C}$ (about $60 \mathrm{~N} /$ pellet). For the TG-DTG curve, the mass loss rate was increasing at $1000^{\circ} \mathrm{C}$. From the discussion of section 3.3, the reduction reaction of $\mathrm{Fe}_{3} \mathrm{O}_{4} \rightarrow \mathrm{FeO}$ was just over and the highest concentration of $\mathrm{FeO}$ existed at about $1000^{\circ} \mathrm{C}$. After $1000^{\circ} \mathrm{C}$, iron started to be produced, making the thermal strength increased.

The carbon gasification reaction occurred rapidly after $1000^{\circ} \mathrm{C} .{ }^{16)} \mathrm{SEM}$ and XRD of the center part of ICP with different reducing agent after reduction at different temperatures was shown in Figs. 7 and 8. The metal iron began to be mass-produced after $1000^{\circ} \mathrm{C}$, which was also a direct cause of higher cold strength after reduction of ICP. ${ }^{18)}$ Before $1000^{\circ} \mathrm{C}$, there was none metal iron but much $\mathrm{FeO}$ and $\mathrm{Fe}_{3} \mathrm{O}_{4}$ produced. However, the morphology of the metal iron produced by different reducing agents was different at $1200^{\circ} \mathrm{C}$. The size of the metallic iron grains produced by bituminous coal was mostly less than $10 \mu \mathrm{m}$, and a few fine grains were adhered to each other. Whereas, the size of the metallic iron grains produced by anthracite and coke powder

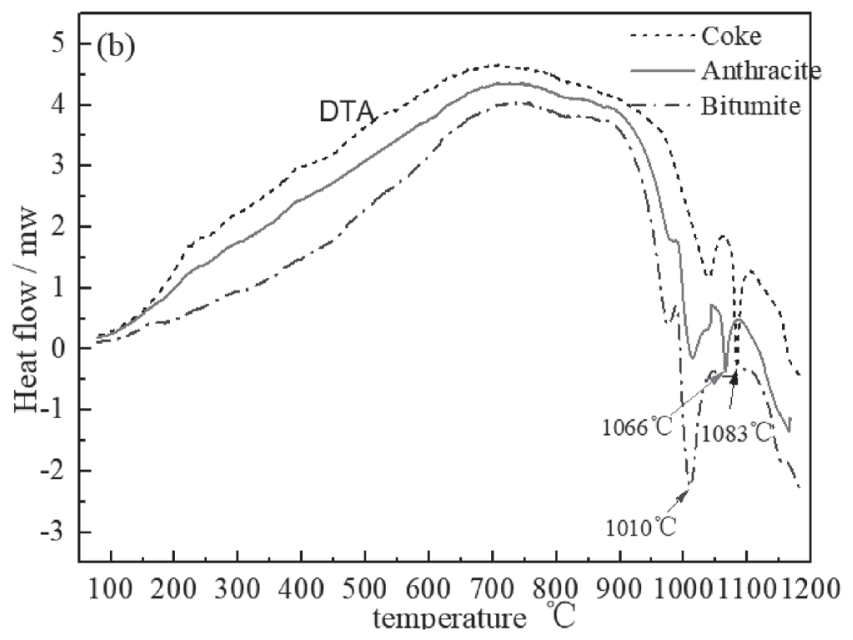

Fig. 6. TG/DTG (a) and DTA (b) curves of non-isothermal reduction process of ICP with different reducing agents. 

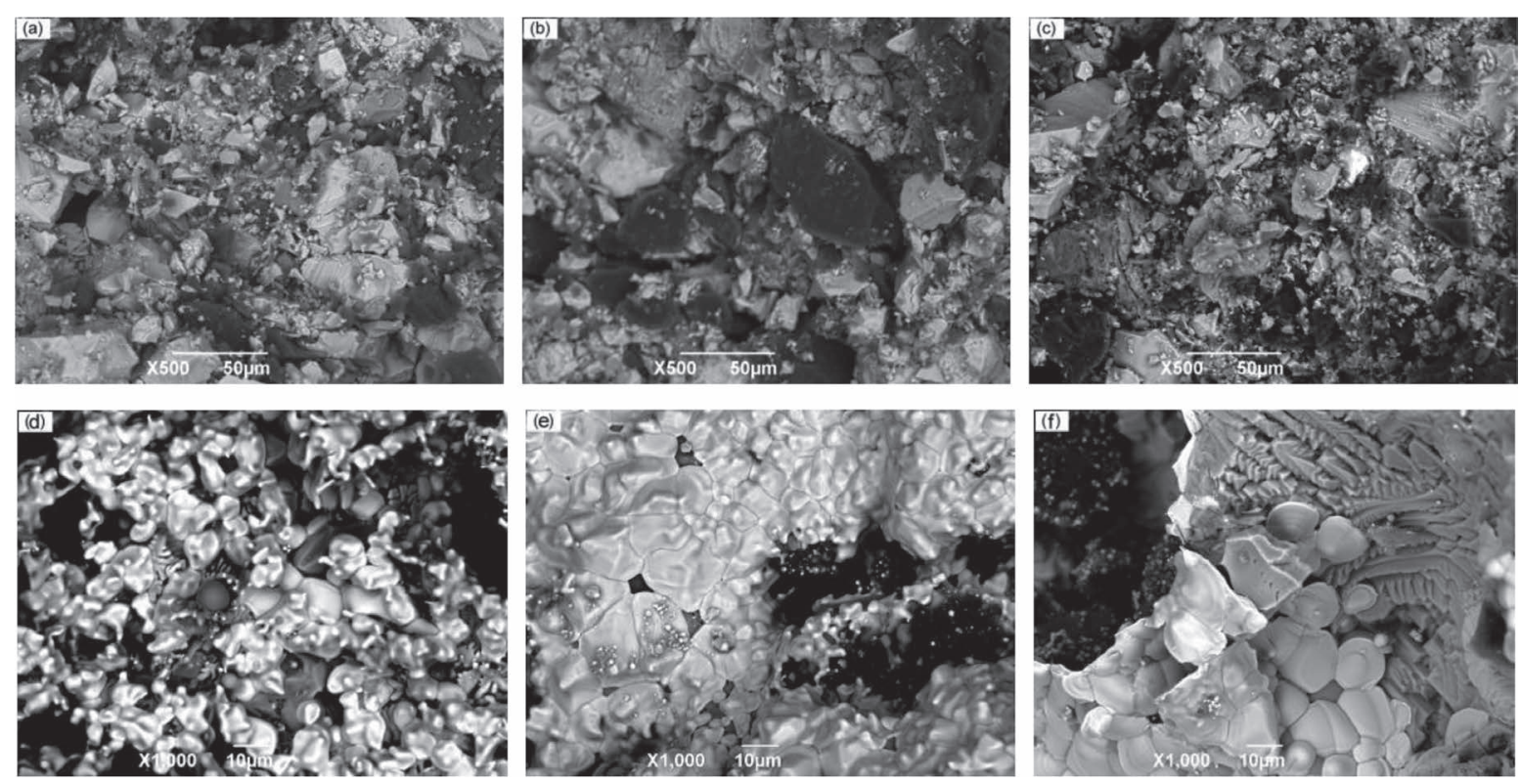

Fig. 7. SEM of ICP with different reducing agent after reduction at different temperatures: (a) bituminous at $800^{\circ} \mathrm{C}$, (b) anthracite at $800^{\circ} \mathrm{C}$, (c) coke at $800^{\circ} \mathrm{C}$, (d) bituminous at $1200^{\circ} \mathrm{C}$, (e) anthracite at $1200^{\circ} \mathrm{C}$, (f) coke at $1200^{\circ} \mathrm{C}$.

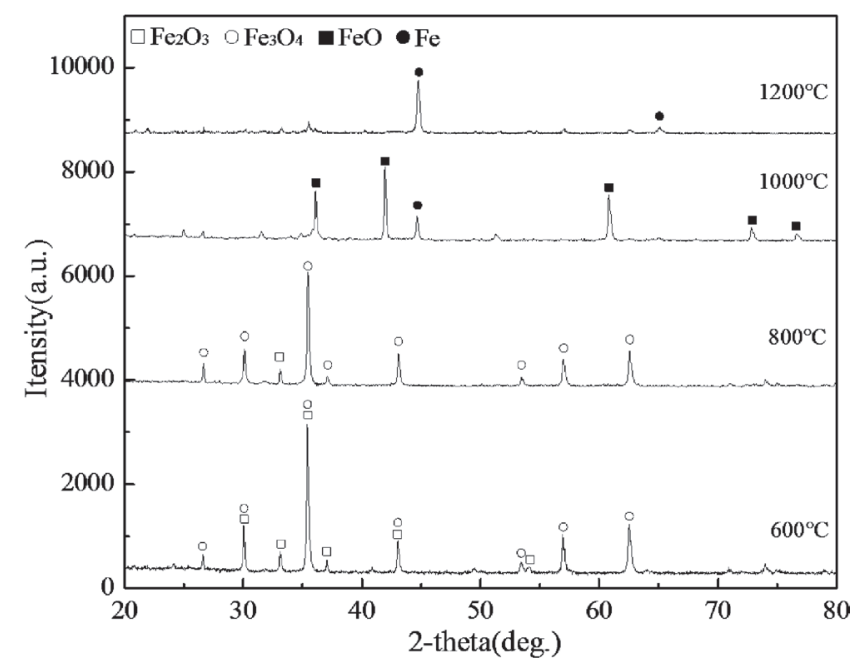

Fig. 8. XRD of ICP with anthracite after reduction at different temperatures.

was large, composed by several grains.

\subsection{Effect of Porosity on Thermal Strength}

Due to the combined water evaporation, the reducing agent volatilization and the reduction reaction, the porosity of ICP was also changed significantly. Figure 9 shown the sample porosity after reduction by different reducing agents. Before $1000^{\circ} \mathrm{C}$, the porosity of ICP increased with the temperature. Compared with $400^{\circ} \mathrm{C}$, the porosity of ICP at $1000^{\circ} \mathrm{C}$ increased by $46.2 \%$ for the ICP with coke powder, $70.6 \%$ for the ICP with anthracite, and $81.6 \%$ for the ICP with bituminous. The porosity of ICP with bituminous coal increased rapidly at $400^{\circ} \mathrm{C}-800^{\circ} \mathrm{C}$, but the porosity of ICP with coke powder and anthracite increased obviously at $800^{\circ} \mathrm{C}-1000^{\circ} \mathrm{C}$. After $1000^{\circ} \mathrm{C}$, the porosity of all pellets gradually decreased with the increase of temperature. The change regulation of porosity was opposite to that of thermal strength, especially at $1000^{\circ} \mathrm{C}$ where the porosity was the highest but the thermal strength was the lowest indicating

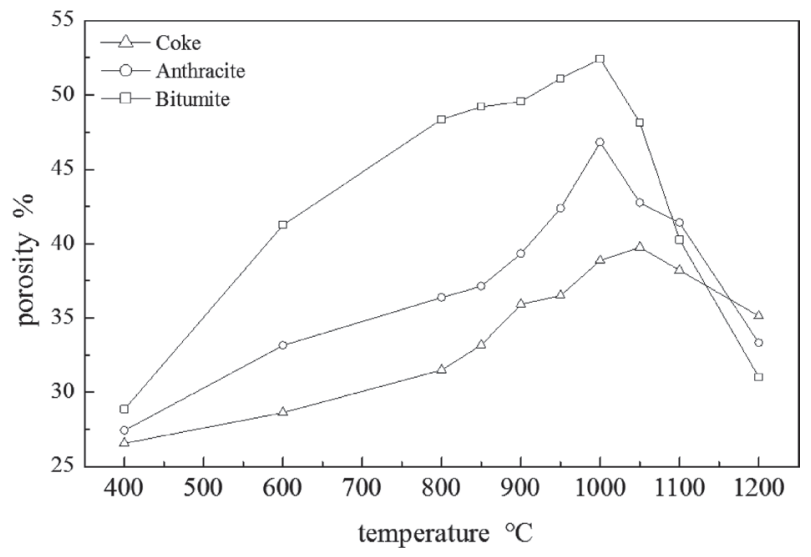

Fig. 9. The porosity of different ICP after the reduction at different temperatures (heating rate $20^{\circ} \mathrm{C} / \mathrm{min}$ ).

that the porosity changes of ICP had great influences on the thermal strength.

Figure 10 gave the scanning electron microscope (SEM) images of ICP with anthracite at different temperature after reduction. At $600^{\circ} \mathrm{C}$, the edge of iron ore particles and reducing agent particles was clear and kept complete, indicating that the reduction inside the pellet occurred weekly. At $800^{\circ} \mathrm{C}$, the edge of iron ore particles was still clear, some small cracks appeared on the small size iron ore particles. But the edge of reducing agent particles become blurred. Combined with the reduction mechanism of ICP, it was concluded that the solid - solid direct reduction reaction and carbon gasification reaction occur in the pellet at this temperature. At $1000^{\circ} \mathrm{C}$, the edge of the iron ore particles was blurred, the boundary between iron ore particles and reducing agent particles was not easy to distinguish, the reducing agent particles with small size greatly reduced, and the inner structure of the pellet became loose. At $1200^{\circ} \mathrm{C}$, the iron ore particles completely disappeared, and the metal iron generated from the reduction connected into a sheet. Overall, the distribution of internal hole was basic consistent 

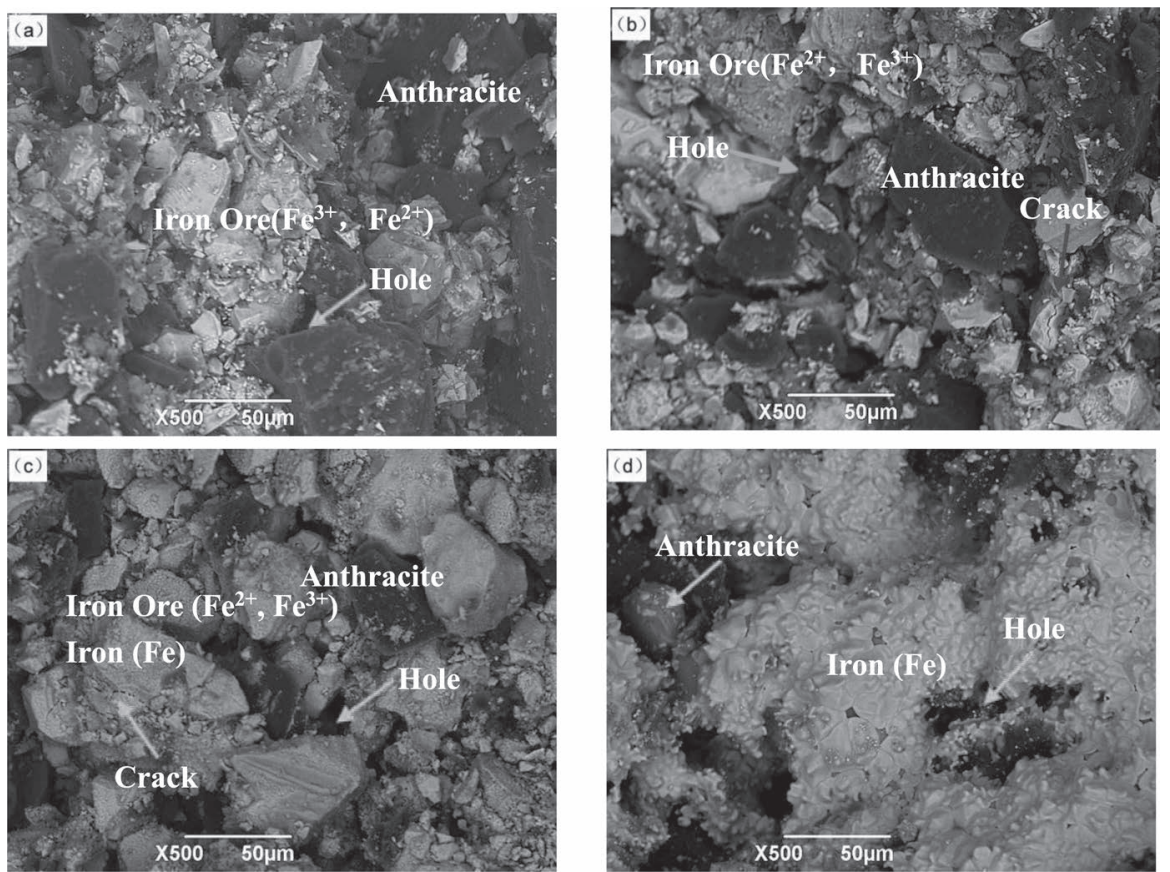

Fig. 10. SEM images of ICP with anthracite after reduction at different temperatures.

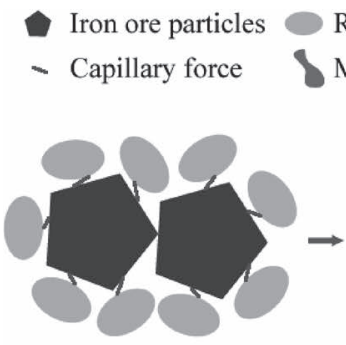

Room temperature
Reducing agent particles

Metal ferrous grains

() Initial outline of particles

Slag phase

- Molecular attraction and viscous force

Fig. 11. The mechanism of thermal strength of ICP at different temperatures.

with the apparent porosity, the sectional area of the hole is the largest at $1000^{\circ} \mathrm{C}$.

\subsection{Mechanism of Thermal Strength of ICP}

Capillary force, viscous force and chemical adsorption played a decisive role in the strength of green pellet, and the contribution of them was different for different binder. ${ }^{19)}$ When bentonite was used as the binder, the capillary force was strengthened by directional arrangement of water molecules between the material particles, increasing the viscosity of the bridge fluid and the viscous force, thereby enhancing the pellet strength. ${ }^{18)}$ However, due to the poor hydrophilicity of the carbonaceous reducing agent particles, the bridging effect of bentonite was limited and the viscous force on the material was reduced. ${ }^{18,20)}$ The mechanism of thermal strength of ICP at different temperatures was discussed based on the composition of raw materials, the properties of raw materials and the preparation method, combined with the two-step reduction mechanism, ${ }^{20)}$ shown in Fig. 11.

At $200^{\circ} \mathrm{C}-800^{\circ} \mathrm{C}, \mathrm{Fe}_{\mathrm{x}} \mathrm{O}_{\mathrm{y}}$ can be reduced directly by the carbon in the reducing agent and reduced indirectly by $\mathrm{CO}$ produced from the reduction. The reduction rate was very slow because of the low temperature, making the physical structure and size of the iron ore and the reducing agent changed little. The increase of the porosity of the pellets was mainly due to the volatilization of the reducing agent. The capillary force disappeared after the loss of water in the pellet. The mainly reaction at these temperatures was $\mathrm{Fe}_{2} \mathrm{O}_{3} \rightarrow \mathrm{Fe}_{3} \mathrm{O}_{4} \rightarrow \mathrm{FeO}$, there is no metal iron appeared, so the thermal strength of the pellets was mainly due to the molecular attraction between the particles and the viscous force of the bentonite binder. At $800^{\circ} \mathrm{C}-1000^{\circ} \mathrm{C}$, the reducing agent was consumed by the carbon gasification and the iron oxide reduction, making the particle size reduced and the gap appeared between the different particles. Iron ore started to be reduced to $\mathrm{FeO}$ and metal iron from $\mathrm{Fe}_{3} \mathrm{O}_{4}$, but the metal iron generated less and grain size was small. So, the pellet porosity increased rapidly. The thermal strength of pellet was still hold by the molecular attraction between the particles and the viscous force of the bentonite binder. At $1000^{\circ} \mathrm{C}-1200^{\circ} \mathrm{C}$, the reduction of iron ore became quickly and the reducing agent reduced substantially, making the pellets shrunken obviously. The number of metallic iron grains increased gradually and grew into a sheet, especially at $1200^{\circ} \mathrm{C}$, most of the reducing agents disappear and iron occupies most of the area, shown in Fig. 10. So, the porosity of the pellet decreased rapidly and the thermal strength of pellet increased.

Three reducing agents used in this study were all hydrophobic raw materials. The fixed $\mathrm{C}$ content in anthracite and 
Table 4. Metallization degree of bituminous ICP with different ratios of $\mathrm{C}_{\text {fix }} / \mathrm{O}_{\text {iron }}$ oxide after reduction at $1000^{\circ} \mathrm{C}$ and $1200^{\circ} \mathrm{C}$.

\begin{tabular}{ccccccc}
\hline \multirow{2}{*}{$\mathrm{C}_{\text {fix }} / \mathrm{O}_{\text {iron oxide }}$} & \multicolumn{3}{c}{$1000^{\circ} \mathrm{C}$} & \multicolumn{3}{c}{$1200^{\circ} \mathrm{C}$} \\
\cline { 2 - 7 } & Total Fe & Metal Fe & $R_{m}$ & Total Fe & Metal Fe & $R_{m}$ \\
\hline 0.9 & 60.82 & 36.89 & 60.65 & 66.96 & 56.56 & 84.47 \\
1.0 & 59.75 & 36.89 & 61.73 & 69.15 & 63.35 & 91.62 \\
1.1 & 61.46 & 38.22 & 62.18 & 70.38 & 64.93 & 92.25 \\
\hline
\end{tabular}

coke powder was higher than that in bituminous coal. Under the same ratio of carbon and oxygen, the ratio of reducing agent and iron ore in ICP with bituminous was higher than that in ICP with anthracite and coke powder. Therefore, the viscous effect of bentonite in the ICP with anthracite and coke powder was weaker than that of the ICP with bituminous. However, when ICP was heated and lost water, the viscous effect of bentonite disappeared. So, the thermal strength after dehydration was very low. After $1000^{\circ} \mathrm{C}$, the thermal strength of the ICP was determined by the formation and growth of the iron joined crystal.

The $\mathrm{C} / \mathrm{O}$ ratio of raw materials also effects the thermal strength of ICP. High $\mathrm{C} / \mathrm{O}$ ratio shows high reducing agent in ICP. Due to the lower molecular attraction and viscous force between coal or coke particles and bentonite binder, the thermal strength of ICP decreases with the increase of $\mathrm{C} / \mathrm{O}$ ratio at the same temperature before $1000^{\circ} \mathrm{C}$. However, when the temperature higher than $1000^{\circ} \mathrm{C}$, high $\mathrm{C} / \mathrm{O}$ ratio is better for the reduction of $\mathrm{FeO} \rightarrow \mathrm{Fe}$. Table 4 shows the metallization degree of ICP increases with $\mathrm{C} / \mathrm{O}$ ratio at $1000^{\circ} \mathrm{C}$ and $1200^{\circ} \mathrm{C}$. The increase of metallic iron grains makes the thermal strength of ICP increase. The thermal strength of ICP with different $\mathrm{C} / \mathrm{O}$ ratio is nearly the same, only $0.9 \mathrm{C} / \mathrm{O}$ ratio at $1200^{\circ} \mathrm{C}$ is lower than other $\mathrm{C} / \mathrm{O}$ ratios because that there is not enough carbon to reduce iron ore to metallic iron for $0.9 \mathrm{C} / \mathrm{O}$ ratio. In fact, the metallization degree of ICP with $0.9 \mathrm{C} / \mathrm{O}$ ratio is $84.47 \%$, lower than that with 1.0 and $1.1 \mathrm{C} / \mathrm{O}$ ratio, shown in Table 4.

When the ICP is taken into the high temperature, the outer layer of pellet is heated through radiation heat transfer at first, and then the heat is transferred into the interior of pellet. According to Stefan-Boltzmann's law and the heat transfer mechanism of the lattice vibration, when the temperature is higher, the outer layer gains greater heat radiation, intensifying the lattice vibration and deliver heat rapidly to the low temperature region of the pellet. In addition, the pore of the pellet can cause convection heat transfer under the condition of high temperature, which contribute to improve the thermal conductivity of the pellet. Therefore, increasing the heating rate to shorten the time to reach the temperature of the intense carbon gasification, or appropriately increasing the proportion of the reducing agent to increase the partial pressure of the reducing gas, will facilitate the rapid reduction of the iron oxide and improve the thermal strength of ICP.

\section{Conclusions}

Through this study, the following conclusions were drawn:
(1) When ICP was damaged by external force at high temperatures, it existed in two states: crush at $200^{\circ} \mathrm{C}-1000^{\circ} \mathrm{C}$ and plastic deformation after $1000^{\circ} \mathrm{C}$.

(2) The change of apparent porosity and thermal strength of ICP in the reduction process can be divided into three stages. At $200^{\circ} \mathrm{C}-800^{\circ} \mathrm{C}$, the apparent porosity increased because the loss of volatiles of the reducing agent, and thermal strength was a little larger than the strength of dried pellet. At $800^{\circ} \mathrm{C}-1000^{\circ} \mathrm{C}$, the carbon gasification and the reduction occurred strongly, making the apparent porosity increased and the thermal strength decreased significantly. At $1000^{\circ} \mathrm{C}-1200^{\circ} \mathrm{C}$, the reduction rate achieved the fastest value, the iron grains gradually grew up and formed many large areas of iron crystal. The pellet occurred a larger contraction, causing the apparent porosity significantly reduced and the thermal strength quickly increased.

(3) The thermal strength of ICP was changed by the combination of combined water evaporation, the reducing agent volatilization and the reduction reaction. At $200^{\circ} \mathrm{C}-1000^{\circ} \mathrm{C}$, the thermal strength was derived from the molecular attraction between the particles and viscous force from bonding agent. But when the temperature higher than $1000^{\circ} \mathrm{C}$, the thermal strength was served by metal iron continuous crystal.

\section{Acknowledgments}

The authors would like to acknowledge the funding from the Natural Science Foundation of China (Project No. 51574002, No. 51274003 and No. 51404005) and Young Teachers' Scientific Research Fund Project of Anhui University of Technology (No. QZ201604).

\section{REFERENCES}

1) Q. Wang: Iron Ore Pellets Containing Carbon Technology, Metallurgical Industry Press, Beijing, (2004), 161.

2) M. K. Sharma, V. Solanki, G. G. Roy and P. K. Sen: Ironmaking Steelmaking, 40 (2013), 590.

3) M. C. Mantovani and C. Takano: ISIJ Int., 40 (2000), 224.

4) S. M. Jung and S. H. Yi: Ironmaking Steelmaking, 41 (2014), 38.

5) M. S. Chu, Z. C. Wang, Z. G. Liu and J. P. Lu: Chin. J. Process Eng., 10 (2010), 121.

6) Y.Ueki, T. Maeda, M. Shimizu, Y. Matsui and A. Kasai: Tetsu-to-Hagané, 89 (2003), 1205.

7) Y. Matsui, M. Sawayma and A. Kasai: ISIJ Int., 43 (2003), 1904.

8) S. L. Liu, C. G. Bai, T. Hu, X. W. Lu and G. B. Qiu: J. Iron Steel Res., 23 (2011), 5.

9) R. C. Nascimento, M. B. Mourão and J. D. T. Capocchi: Ironmaking Steelmaking, 26 (1999), 182.

10) H. Q. Tang, X. M. Guo, S. B. Zhang and Z. C. Guo: J. Iron Steel Res., 12 (2000), 1.

11) J. Y. Shi and E. Donskoi: Math. Comput. Model., 42 (2005), 45

12) H. W. Cheng, X. G. Lu, Q. Li, C. Y. Chen and K. C. Chou: J. Chin. Rare Earth Soc., 26 (2008), 103.

13) X. W. An, J. S. Wang, X. F. She, Y. G. Ding and Q. G. Xue: J. Univ. Sci. Technol. Beijing, 35 (2013), 155.

14) H. Konishi, A. Yamashita and T. Usui: ISIJ Int., 50 (2010), 386.

15) K. Wu, Y. H. Qi, J. W. Zhao, G. S. Feng and C. R. Du: J. Univ. Sci. Technol. Beijing, 22 (2000), 101.

16) R. Wei, D. Cang, L. Zhang and Y. Bai: Int. J. Min. Metall. Mater., 22 (2015), 1025.

17) J. X. Li, R. F. Wei, H. M. Long, P. Wang and D. Q. Cang: Powder Technol., 262 (2014), 30.

18) R. F. Wei, J. X. Li, G. W. Tang and D. Q. Cang: Ironmaking Steelmaking, 41 (2014), 514.

19) G. Z. Qiu, T. Jiang and X. H. Fan: Scand. J. Metall., 33 (2004), 39.

20) H. Park and V. Sahajwalla: ISIJ Int., 54 (2014), 1256. 